\title{
Correction to: Challenges Ahead
}

Tonglei Li'

Published online: 29 March 2021

(C) Springer Science+Business Media, LLC, part of Springer Nature 2021

\section{Correction to: Pharmaceutical Research volume 38,} page I(202I).

https://doi.org/ | 0.1007/s I | 095-02 I03004-0

This correction is to update reference 1 .

Yu, Y.B., Briggs, K.T., Taraban, M.B., Brinson, R.G., Marino, J.P. Grand Challenges in Pharmaceutical Research Series: Ridding the Cold Chain for Biologics. Pharm Res 38, 3-7 (2021).

The original article has been corrected.

The online version of the original article can be found at https://doi.org/l 0 . |007/s | |095-021-3004

$\triangle$ Tonglei Li

tonglei@purdue.edu

\footnotetext{
Department of Industrial and Physical Pharmacy, College of Pharmacy,

Purdue University, West Lafayette, Indiana 47907, USA
} 